\title{
The Suitability of 3D Data: 3D WAE Digitisation of Human Remains
}

Suzanna White iD, Institute of Archaeology, University College London, 31-34 Gordon Square, London, WC1H OPY, UK; Department of Anthropology, University College London, 14 Taviton Street, London, WC1H OBW, UK

E-mail: suzanna.white.13@ucl.ac.uk

Cara Hirst, Institute of Archaeology, University College London, 31-34 Gordon Square, London, WC1H OPY, UK

Sian E. Smith, Institute of Archaeology, University College London, 31-34 Gordon Square, London, WC1H OPY, UK; Centre for the Forensic Sciences, University College London, 35 Tavistock Square, London, WC1H 9EZ, UK; Department of Security and Crime Science, University College London, 35 Tavistock Square, London, WC1H 9EZ, UK

\section{ABSTRACT}

The use of 3D data in the analysis of skeletal and fossil materials has conveyed numerous advantages in many fields; however, as the availability and use of 3D scanning equipment are rapidly increasing, it is important for researchers to consider whether these methods are suitable for the proposed study. The issue of suitability has been largely overlooked in previous research; for instance, casts and reconstruction methods are frequently used to increase sample sizes, without sufficient assessment of the effect, this may have on the accuracy and reliability of results. Furthermore, the reliability of geometric morphometric methods and the implications of virtual curation have not received sufficient consideration. This paper discusses the suitability of $3 D$ research with regard to the accuracy, reliability, and accessibility of methods and materials, as well as the effects of the current learning environment. Areas where future work will progress 3D research are proposed.

Résumé: L'utilisation de données 3D dans l'analyse de matériaux squelettiques et fossiles a fourni de nombreux avantages dans plusieurs domaines, mais comme la disponibilité et l'utilisation de l'équipement de balayage 3D connaissent une montée rapide, les chercheurs doivent se demander si ces méthodes conviennent à l'étude proposée. Le problème de la convenance a été largement ignoré dans les recherches précédentes. Pour cas, des méthodes de moulage et de reconstruction sont souvent utilisées pour augmenter la taille des échantillons sans d'abord évaluer avec précision l'effet de celles-ci sur l'exactitude et la fiabilité des résultats. Qui 
plus est, la fiabilité des méthodes morphométriques géométriques et les répercussions de la conservation virtuelle n'ont pas fait l'objet de suffisamment d'attention. Le présent article discute de la convenance des recherches 3D relativement à l'exactitude, la fiabilité et l'accessibilité des méthodes et matériaux, ainsi que des effets de l'environnement d'apprentissage actuel. Nous y proposons des domaines où les travaux futurs feront avancer la recherche 3D.

Resumen: El uso de datos tridimensionales en el análisis de material esqueléticos y fósiles ha proporcionado numerosas ventajas en muchos campos, sin embargo, dado que la disponibilidad y el uso de equipos de escaneo en 3D está aumentando rápidamente, es importante que los investigadores consideren si estos métodos son adecuados para el estudio propuesto. En gran parte el tema de la idoneidad ha sido pasado por alto en investigaciones previas; por ejemplo, con frecuencia se utilizan moldes y métodos de reconstrucción para aumentar el tamaño de las muestras, sin una evaluación suficiente del efecto que esto puede tener en la precisión y confiabilidad de los resultados. Además, la confiabilidad de los métodos morfométricos geométricos y las implicaciones de la conservación virtual no han recibido suficiente consideración. Este documento discute la idoneidad de la investigación tridimensional con respecto a la precisión, confiabilidad y accesibilidad de los métodos y materiales, así como los efectos del entorno de aprendizaje actual. Se proponen áreas de trabajo futuro que harán que la investigación en 3D progrese.

\section{KEY WORDS}

3D digitisation, Geometric morphometrics, Accuracy, Reliability, Accessibility, Suitability

\section{Introduction}

Digital imaging methods are steadily gaining prominence in the fields of archaeology and anthropology. Recent technological advances have meant that the software and hardware required to create high-quality, accurate digital representations of specimens are more available and accessible to an increasing number of researchers. However, as virtual anthropology and archaeology are relatively young fields, they bring with them new methodologies that need to be rigorously tested to ensure they are suitable for the 
analyses to which they are applied. To do this, researchers must assess the reliability, accuracy, and practical applications of different 3D digitisation methods. Additionally, our understanding of the holistic potential of 3D digitisation must be improved to stimulate the development of this field and increase the accessibility of digital techniques and data.

Suitability of 3D digitisation methods can be assessed from multiple perspectives. Firstly, in terms of how useful they are: do results gained from these applications provide substantially more information than established methods? Secondly, from a perspective of scientific credibility: is the data produced with these methods sufficiently precise, accurate, and reliable to meet a robust scientific standard? And thirdly, in terms of accessibility: are the equipment and software required affordable and relatively user-friendly, and do data produced from these methods offer a significant advantage in increased accessibility? These three points will be explored largely from an anthropological viewpoint, focusing on osteoarchaeology, forensic anthropology, and palaeoanthropology, but this article will also consider innovative approaches from other fields such as heritage and archaeological conservation.

\section{D Digitisation Methods}

Anthropologists and archaeologists have become innovators in the application of 3D digitisation methods (Bookstein and Weber 2011). However, many of the techniques used have been integrated from other disciplines, such as engineering and medical science. Digital visualisation and rapid prototyping of structures are crucial to modelling structures, enable reconstruction in these fields (Choi et al. 2002), and make digitisation methods ideal for transfer to anthropological contexts. This, however, also means that we are relying on the accuracy validations and standard practices primarily developed for medical and engineering researches. It is important, therefore, to assess the applicability of these methods to osteological research and choose digitising equipment and parameters accordingly.

Traditional anthropometry is a key aspect of anthropology and osteoarchaeology and involves the use of basic two-dimensional (2D) measurements, typically between well-defined landmarks. These measurements have many applications, from guiding medical practitioners in craniodental surgery (Covino et al. 1996), to assessing variation within skeletal collections from across the world (Howells 1973). The development of 3D geometric morphometrics (Bookstein et al. 2004; Bookstein 1991; Rohlf and Rohlf 1990) increased the applicability of such methods by allowing 3D objects to be recorded in a data format that preserves the underlying geometric relationship between points (Bookstein 1991; Mitteroecker and Gunz 
2009). Methods of collecting three-dimensional (3D) data range from the use of coordinate measurement machines (or digitisers) such as MicroScribes, to more high-coverage methods, such as X-ray computed tomography (including micro-CT), laser scanning, structured-light scanning, and 3D photogrammetry.

\section{Efficacy}

For $3 \mathrm{D}$ digitisation methods to be shown to be suitable in anthropology, we must examine their efficacy. As with all innovative technology, there is an impulse to apply increasingly more impressive techniques to new research to increase the impact of the results. This is especially true of $3 \mathrm{D}$ digital methods, where visually stunning images can be produced. However, researchers must be applying the most appropriate method; this means prioritising methodological efficiency and focusing on answering the scientific question(s) at hand, rather than what can be achieved with $3 \mathrm{D}$ techniques (Pletinckx 2011). Therefore, before implementing the most complex methodology, researchers should use a cost-benefit analysis approach to assess the possible improvement of quality in results, as well as time and cost benefits that $3 \mathrm{D}$ methods could have over more traditional methods.

3D digitisation of anthropological material can be a time-consuming endeavour. Surface-scanning and 3D photogrammetry require some learning time as well as practise developing an appropriate approach to capture the complete morphology of the object of interest. Both also require processing of resulting images to create the final digital object, although this varies between methods and is being reduced by the development of semiand fully-automated programs in some cases (Guyomarc'h et al. 2012; Jaklič et al. 2015). CT scanning, on the other hand, can require a considerable time-commitment, access to an appropriate CT (or micro-CT) scanner which is large enough to fit the research specimen, transport of the specimen to a suitable scanner, funds to pay for the CT scanning and processing time if a researcher has to visit an external facility, as well as either access to a technician or appropriate operation knowledge, and a computer with the correct software and capacity to generate the CT data. The resulting data again require considerable processing before they can be used effectively. In contrast, traditional osteometric methods are typically easy to learn, and the processing required is minimal in comparison with $3 \mathrm{D}$ digitisation. Nevertheless, some researchers have suggested that methods such as $3 \mathrm{D}$ digitisation require significantly less time to collect comparable datasets to traditional osteometrics (Boyer et al. 2015; Hildebolt and Vannier 1988), meaning that when the process is considered as a whole, digiti- 
sation may be equally time-efficient to more traditional methods of data recording, depending on the nature of the required dataset.

3D methods also require a range of specialised equipment and software. These systems often function with unique file formats, increasing the cost of purchasing and using certain methods, especially in the case of laser, structured-light, and CT scanning. As proprietary software tends to be expensive, there have been recent developments of open-source and free alternatives to support the different processing stages of 3D methods, such as packages in $\mathrm{R}$ ( $\mathrm{R}$ Core Team 2014), Meshlab (Visual Computing Lab ISTI-CNR), Blender (Blender Online Community), ImageJ (Rueden et al. 2016, 2017; Schneider et al. 2012), and 3D Slicer (Fedorov et al. 2012).

$3 \mathrm{D}$ photogrammetry offers a low cost alternative to other 3D digitisation methods. 3D photogrammetry has been demonstrated as a suitable imaging method in fields such as archaeology (Noya et al. 2015), forensic medicine (Thali et al. 2003), anthropology (Sansoni et al. 2009), and engineering (Rodríguez-Martín et al. 2016). It uses simple photography equipment that can be customised with different settings, lenses, and lighting to suit the resolution requirements of the analysis (eg Gallo et al. 2014). Additionally, methodological developments have improved time efficiency with automated and semi-automated image capture, lighting systems, and image processing (Hirschmuller and Hirschmuller 2005; Remondino 2011; Streilein 1994). Consequently, 3D photogrammetry is a cost- and time-efficient method for digital measurement, enhanced surface visualisation, and object preservation. With the constant development of low-cost methods such as 3D photogrammetry, 3D imaging is becoming more accessible (see below) for systematic use and integration with current practices.

There can be clear advantages to 3D digitisation over other recording techniques. For instance, fragile and otherwise inaccessible material can be examined, and affordable, high-quality replicas produced for display, teaching, and research. The first of these advantages was realised very early in the application of 3D methods to palaeontology; CT scanning was used to examine fossil crania where elements were trapped in soil matrices (Conroy and Vannier 1984) and to assess the internal structures of fossil Homo erectus crania (Wind 1984). In osteoarchaeology, it was used in the study of mummies (Hjalgrim et al. 1995; Zur Nedden et al. 1994) and fragmentary skeletal material (Lynnerup et al. 1997). Such applications allowed researchers to analyse aspects of internal morphology that were inaccessible through traditional examination, and subsequently inform conservation strategies.

The ability to produce replicas from digital data was again borrowed from engineering and medicine (Ashley 1991; Hjalgrim et al. 1995). Rapid prototyping was quickly applied to anthropological contexts (Seidler 1997; 
Zollikofer et al. 1998), originally using machinery-based milling to create replicas from CT data (Barker et al. 1994). Stereolithography (SL) replaced milling and turning machines as a more suitable alternative in the 1980s, as it could replicate internal structures by a process which builds models layer by layer, through selective solidification of a liquid monomer (Barker et al. 1994; Ebert et al. 2011; Hull 1986; Mankovich et al. 1990). In more recent years, developments in $3 \mathrm{D}$ printing technology such as fused deposition modelling (FDM) and selective laser sintering (SLS) have allowed more researchers to create accurate physical 3D models, in shorter time periods, and at low costs (approximately one-third or less of a SL model (Cohen et al. 2009; Ebert et al. 2011)). These replicas have many potential uses, which are discussed below.

\section{Scientific Validity}

The scientific validity of 3D digitisation methods in archaeology and anthropology is yet to be fully established (Pletinckx 2011). Validation requires that these methods be demonstrated to be precise, accurate, and reliable. Additionally, the introduction of standardised methodologies is essential in ensuring high-quality results (see Hirst et al. 2018). The origin of these methods in medical sciences and engineering has already established some of these qualities. For instance, studies have shown that there are no significant differences between measurements taken from $3 \mathrm{D}$ virtual models generated from CT data in comparison with those generated through traditional osteometrics (Covino et al. 1996; Hildebolt et al. 1990; Spoor et al. 1993). However, others have shown a mean difference of $0.49 \mathrm{~mm}$ (Choi et al. 2002) and indicated that 3D CT models may lead to systematic underestimations of between 0.06 and $1.01 \mathrm{~mm}$ (Guyomarc'h et al. 2012).

As 3D digitisation technology is introduced to archaeology and anthropology, researchers are beginning to test their accuracy as well. Comparisons between methods have indicated that results are very similar ( $<1 \mathrm{~mm}$ error); surface models produced with 3D photogrammetry have been found to show low deviation to those produced by $3 \mathrm{D}$ surface scanners (Katz and Friess 2014); and models from cone beam CT scan data have been found to be slightly more accurate than laser scanner models, or those produced by 3D stereophotogrammetry (Fourie et al. 2011). Nevertheless, significant errors have been found between data produced using different types of 3D digitisers (Ross and Williams 2008), indicating internal inconsistency within accuracy assessment methods. Digitisers have also been shown to result in relatively high differences in comparison with $3 \mathrm{D}$ CT methods (Richtsmeier 1995), and while some studies indicate they pro- 
duce significantly more accurate results than 3D laser scans (Sholts et al. 2011), others have found the two methods to be largely comparable (Algee-Hewitt and Wheat 2016). Further studies have indicated that the accuracy of results between data collection methods is dependent on the state of the material in question, with more tactile techniques where data can be collected directly from the object, such as traditional anthropometry and the use of 3D digitisers, generating more reliable and accurate results than virtual techniques for specimens affected by some kinds of taphonomic damage (Sholts et al. 2011).

As the integration of 3D methods into archaeological and anthropological analyses increases, identification and mitigation of their limitations need to be considered. Some initial errors that can be encountered are a direct result of the equipment and scan parameters used to produce a digital image. For laser scanning, the quality of the resulting model is affected by the settings used (eg how many scans, point density, and mode) (Polo and Felicísimo 2012), as well as the positioning of the object (Fourie et al. 2011), the environmental conditions (Algee-Hewitt and Wheat 2016), and the method used to align individual scans (Fourie et al. 2011; Guyomarc'h et al. 2012). In 3D photogrammetry, the camera must be calibrated prior to image capture to eliminate distortion, and the final quality of the 3D model is affected by the quantity of images captured (Gallo et al. 2014). In CT scanning, the accuracy of the image produced is dependent on the slice thickness (Choi et al. 2002; Jung et al. 2002), the positioning of the object in relation to the X-ray beams (Covino et al. 1996), the particular method of CT scanning used (eg cone beam vs. conventional CT scanning), as well as numerous other factors (Barker et al. 1994; Choi et al. 2002).

Another source of error specific to 3D models generated from CT data is the computer algorithm used to separate out the material of interest and interpolate the slices into a $3 \mathrm{D}$ volume. Various processes, both manual and automated, exist (eg those in Buie et al. 2007; Dunmore et al. 2018) for assessing the correct threshold required to separate out osseous material from surrounding tissue or mounts. These processes have been shown to affect the quality of the resulting image (Guyomarc'h et al. 2012), with different effects being found for internal and external surfaces (the 'dumb-bell effect') (Choi et al. 2002). This issue is unlikely to be easily resolved, as the correct threshold varies between specimens (Choi et al. 2002), and the process of CT scanning results in a continuous border between different tissues (Guyomarc'h et al. 2012). There are also various methods that can be used to interpolate the slices, smoothing sharp discontinuities between them, and resulting in a 3D surface model (eg the Marching Cubes algorithm-Barker et al. 1994; Lorensen and Cline 1987). Again, the method used will result in a slightly different $3 \mathrm{D}$ representation of the original shape (Choi et al. 2002), and the effects of this are largely unexplored. 
Finally, there are errors associated with the production of physical replicas, as well as with subsequent morphometric analysis. These errors could be due to several factors, such as model shrinkage, smoothing procedures, and filling of holes in preparation of the $3 \mathrm{D}$ surface model prior to production, removal of support structures, and the laser settings and thickness (Barker et al. 1994; Choi et al. 2002; Ebert et al. 2011). While the implications of these estimations of error may be difficult to visualise, qualitative assessment of replicas produced through stereolithography indicates that they may correspond to loss of thinner elements of bone, under-visualisation of foramina, and loss of details in complex areas (Barker et al. 1994).

Despite the demonstration of error between replicas produced through 3D digitisation and the original specimen, it is currently unknown whether this represents significant differences in accuracy in comparison with traditional methods of replica production. Casts produced by moulding of original specimens are commonly used in palaeoanthropology, due to limited access to sparse fossil material. The accuracy of these is questionable and dependent on the material used (eg plaster vs. resin), with some studies indicating a difference of up to $1.55 \mathrm{~mm}$ (Athreya 2009) or approximately 4\% (Holliday et al. 2010) due to phenomena such as shrinkage. More indepth analyses have indicated substantial differences between cast and original data, at times commensurate to inter-species differences (McNulty and Smith 2009). In comparison, 3D printed replicas generated from CT scan data have the potential for higher levels of accuracy (White 2016), although this requires further investigation. What can be concluded is that replicas produced through 3D digitisation methods are potentially as accurate, if not more so, than those produced by traditional methods.

$3 \mathrm{D}$ digitisation and $3 \mathrm{D}$ geometric morphometric methods introduce a greater potential for reconstruction of anthropological specimens. Fossil and archaeological remains are frequently affected by post-depositional distortion and taphonomic processes, resulting in fragmentary specimens. Reconstruction efforts to correct for these effects are dependent on CT scanning (Gunz 2005; Kalvin et al. 1992, 1995; Vannier et al. 1985), and many researchers have developed sophisticated methods of virtual reconstruction, largely influenced by medical research (Benazzi et al. 2009, 2014; Bermúdez de Castro et al. 2016; Dobson et al. 2011; Gunz 2005; Gunz et al. 2009; Ogihara et al. 2006; Ponce de León and Zollikofer 2001; Ponce de León et al. 2011; Senck et al. 2013, 2015; Zollikofer et al. 2005). Reconstruction efforts are crucial to geometric morphometrics, where missing areas result in missing landmark coordinates, and typical statistical approaches cannot be applied, meaning that these data points either need to be ignored for the entire sample, or reconstructed (Gunz 2005; Gunz et al. 2009). Not only does virtual reconstruction of 3D models allow more specimens to be included (Benazzi et al. 2014; Harvati et al. 2004), increas- 
ing the validity of results, it may also allow researchers to explore and model taphonomic processes (Ponce De León and Zollikofer 1999), and investigate aspects of palaeopathology (Milella et al. 2015).

There are numerous reconstruction methods available. The most basic for symmetric specimens such as crania involves the restoration of bilateral symmetry by mirroring complete sections or landmarks across an empirical midplane, reflected relabelling, or reflection using thin-plate splines (TPS) (another principle borrowed from engineering) (Gunz et al. 2009). When a simple reflection-based technique is inapplicable, researchers can exploit the redundancy of information contained in 3D models and our knowledge of biological structures through geometric morphometric methods (Gunz 2005; Gunz et al. 2004, 2005, 2009). This can be achieved via statistical methods, where missing data are estimated through multiple multivariate regressions, or by geometric methods, where the smoothness properties of TPS are used to warp a reference specimen to the morphology of the target specimen (Friess 2010; Gunz et al. 2009; Mitteroecker and Gunz 2009). Reconstruction accuracy is defined as the mean-squared difference between the original and the reconstruction in appropriate units (Gunz et al. 2009). It varies between methods and datasets and can be affected by: the number of data points used, the reference sample or specimen, the area that is being reconstructed, and the effects of asymmetry (Gunz et al. 2009; Senck et al. 2013, 2015). Reconstructions will never be perfect depictions of the original specimen, but rather a suitably accurate representation. Therefore, reconstruction error must be considered when working with 3D digital data. As reconstructions are also uniquely produced by differing methods, the most suitable method will vary depending on the specimen being reconstructed, and the analysis being used. As such, it is unlikely that reconstructions will be completely reliable between studies.

Reliability of the results drawn from 3D data can also be affected by the sources of error discussed above. As discussed, there is a wide range of equipment and software that can be used in 3D digitisation. This, along with the high degree of flexibility that arises from the different settings available, arguably makes each methodology unique, with researchers rarely reporting digitisation parameters in sufficient detail for studies to be replicated. Inter-method reliability, therefore, is both difficult to measure and likely to be low. Despite the popularity of 3D digitisation methods, there is a damaging lack of standardised processes to guide researchers when collecting 3D digital data (see Hirst et al. 2018 for discussion of the effect). 


\section{Accessibility}

If $3 \mathrm{D}$ digitisation methods are to prove suitable for use in archaeology and anthropology, the equipment, and software required need to be accessible to all researchers. As discussed, advances in $3 \mathrm{D}$ digitisation techniques have meant that certain equipment is more easily available to researchers and students, especially in the case of 3D photogrammetry. Software and computing advances have also ensured that researchers can achieve high levels of accuracy and reliability without requiring proprietary software. For example, open-source and free programs such as Meshlab and $\mathrm{R}$ include packages and coding for the various analyses required in geometric morphometrics. Nevertheless, the full potential of virtual anthropology has yet to be achieved, and considerable progress is required to fully realise the implications this field has for accessibility, particularly in the learning environment.

The accessibility of $3 \mathrm{D}$ digital data is particularly relevant to the new field of virtual curation, which is heavily rooted in heritage and conservation. Developments in this area have shown how the 3D digitisation of archaeological and anthropological specimens and landscapes has many useful applications. For instance, resulting data can be used to create highly detailed records of museum objects (Ahmon 2004; Fontana et al. 2002), as demonstrated by projects such as the Virtual Curation Laboratory (Huber 2014; Means et al. 2013), as well as allowing digital preservation of fragile material (Means et al. 2013; Simon et al. 2009) and minimising the damage caused by repeated sampling and handling (Bowron 2003). These records can be used to create virtual exhibitions, both within museums and online (Keklikoglou et al. 2016; Means et al. 2013; Tucci et al. 2011; Ynnerman et al. 2016), which will increase public engagement and accessibility of anthropology and archaeology in an increasingly digital age.

There are other implications of digitisation of archaeological and anthropological materials. Digital records, if made freely available, can be used to create virtual typologies, improving field identification (Means et al. 2013) and allowing researchers to access comparable material when investigating palaeopathological cases (eg the Digitised Diseases project, www.digitiseddiseases.org). These data can be easily disseminated (Ahmon 2004; Simon et al. 2009), either freely or through controlled schemes, potentially easing the role of collection curators. Dissemination of data would also dramatically increase the sample sizes available to researchers and students, encouraging experiential equality among scientists at all levels (Algee-Hewitt and Wheat 2016).

A key advantage of 3D digitisations that has already been established above is the production of accurate replicas, available in several materials 
and at relatively low costs (Lynnerup et al. 1997; Seidler 1997). It has been suggested that these replicas, both physical and virtual, could play a vital role in restoration and conservation. As 3D digitisation techniques do not require contact with the object in question, unlike traditional methods which may cause damage (Ahmon 2004), they can be used on fragile material before restoration work commences. They may shed light on previous alterations (Fontana et al. 2002), allowing reverse engineering of the original artefact, and would enable researchers to easily replicate and reconstruct missing areas, allowing optimal restoration (Fontana et al. 2002; Pletinckx 2011). Digital records could even extend the restoration process into a fourth dimension, allowing researchers to see the evolution of structures over time (Pletinckx 2011). Digitisation may also play a vital role in conservation, serving as a comparison to monitor changes in an artefact or area over time (Ahmon 2004). This has been demonstrated in under-water archaeology, where sites are at high risk of damage due to shipping activity (Jaklič et al. 2015). Nevertheless, the widespread use of 3D digitisation in conservation and heritage may be limited by a lack of long-term preservation of digital data (Pletinckx 2011), which is another issue that should be considered by researchers working in a digital environment.

Replicas produced from digitised data can serve as archaeological and anthropological avatars in museum exhibitions, allowing visitors to engage with artefacts, and in teaching activities (Means et al. 2013). For instance, the British Museum recently displayed the Jericho skull along with two 3D printed replicas, generated from CT data, allowing visitors to see the original cranial form as well as the numerous facial reconstructions that have been created (Hirst 2017). Replicas can also be used in a professional setting, for instance, in the production of reconstructions of injuries in forensic cases, which would allow juries to better visualise certain scenarios (Ebert et al. 2011). In addition, 3D digitisation and replicas may be extremely useful in preserving material that is being reburied (Hjalgrim et al. 1995) or repatriated, although the ethical and practical implications of this process are largely unexplored at present (Smith and Hirst 2018; Hirst et al. 2018).

As can be seen, the accessibility of 3D digitisation of anthropological and archaeological material is directly linked to the efficacy and scientific credibility of this area. Without increased accessibility and wide dissemination of digital data, the potential efficacy of this field is severely limited. Without software, hardware, and raw data being available, reliability of results will undoubtedly decrease, as researchers are forced to implement unique methods to obtain results. While some projects have been established in recent years to increase the availability of digital data (eg MorphoSource (Copes et al. 2016), Digitised Diseases, NESPOS (Weniger 2005), AfricanFossils.org), current efforts are insufficient. As has been 
demonstrated, in fields such as palaeoanthropology, access to primary data is crucial to obtaining valid results (McNulty and Smith 2009; White 2016) and is made possible through $3 \mathrm{D}$ digitisation and virtual curation. While some researchers have recognised this (Hublin 2013; Weber 2001), the dissemination of $3 \mathrm{D}$ fossil data is highly restricted, potentially due to issues of funding and control over future research projects. Nevertheless, work by researchers on the Rising Star Project (Berger et al. 2015; Hawks et al. 2017) has demonstrated the importance of combining rapid 3D digitisation of anthropological remains with free dissemination of data in allowing significant developments in our understanding of the past and 3D methodologies, especially in the case of early career researchers who are frequently excluded from high-impact research due to inaccessibility of data. While there are, of course, ethical considerations, there is clear potential in the wider application of this approach to archaeology, bioanthropology, and the forensic sciences.

\section{Recommendations}

The numerous advantages of 3D digitisation methods are clearly demonstrable in heritage and conservation, palaeoanthropology, bioarchaeology, and the forensic sciences; however, the holistic potential of 3D digitisation methods has not yet been reached. After exploring three key themes linked to suitability of 3D digitisations (efficacy, scientific validity, and accessibility), the following recommendations can be made. Future work in 3D digitisation of human remains should aim to:

1. Consider the efficacy and appropriateness of 3D methods before conducting research in archaeology and anthropology, and continue to apply more traditional methods when appropriate for the research questions at hand.

2. Consider the wider potential for $3 \mathrm{D}$ digital methods at all levels of research and curation, especially in the case of low-cost methods such as photogrammetry.

3. Improve the scientific validity of studies using 3D digital data by implementing more thorough recording of scanning protocols and reporting of error, and show awareness of the numerous potential sources of error associated with each digitisation method.

4. Conduct further research into the precision, reliability, and accuracy of all 3D digitisation methods.

5. Test whether resulting $3 \mathrm{D}$ surface models and replicas made from these models accurately represent the original object, as $3 \mathrm{D}$ methods 
allow an increased opportunity to manipulate and reconstruct specimens.

6. Make methods, equipment, and software more easily accessible to students and researchers at all levels. This can be achieved in two key ways:

a. By lifting restrictions that limit access to $3 \mathrm{D}$ data, either by making data open-access where appropriate, or by implementing controlled schemes that give consideration to the ethical issues involved with representations of human remains.

b. By bringing the theory and practice of $3 \mathrm{D}$ methods into teaching in archaeology and anthropology, enabling the exploration of 3D methods in research and heritage, and improving students' ability to produce original, high-impact research projects.

\section{Conclusion}

The ability of 3D digitisation methods to quickly collect high-quality data from anthropological and archaeological specimens has wide-reaching implications, from conservation and restoration, to public engagement, to the production of replicas and increased accessibility of digital data. Nevertheless, the suitability of these methods must be assessed in terms of efficacy, scientific validity, and accessibility, especially in comparison with traditional methods that may be more time- and cost-efficient. This paper has explored some of these aspects, demonstrating that $3 \mathrm{D}$ digitisation has many advantages over other methods, such as the production of replicas, analysis and description of more detailed aspects of morphology, and assessment of otherwise inaccessible material. While there are numerous sources of error that may affect the accuracy and reliability of 3D data gained through digitisation techniques, the effect of these is comparable to those found in traditional techniques of anthropological and archaeological recording and analysis. While 3D methods have their own drawbacks, recent developments in computer science, equipment production, and geometric morphometrics have meant that increasing numbers of researchers can now access and exploit 3D methods with valid results. Ongoing research into low-cost 3D digitisation methods is improving their accessibility, accuracy, and efficiency, while increasing accessibility of data will allow researchers to sidestep the initial barriers to primary 3D data collection. 


\section{Compliance with Ethical Standards}

Conflict of interest The authors declare that they have no conflict of interest.

\section{Open Access}

This article is distributed under the terms of the Creative Commons Attribution 4.0 International License (http://creativecommons.org/licenses/by/ $4.0 /$ ), which permits unrestricted use, distribution, and reproduction in any medium, provided you give appropriate credit to the original author(s) and the source, provide a link to the Creative Commons license, and indicate if changes were made.

\section{References}

Ahmon, J.

(2004). The application of short-range 3D laser scanning for archaeological replica production: The Egyptian tomb of Seti I. The Photogrammetric Record, 19, 111-127.

Algee-Hewitt, B. F. B., \& Wheat, A. D.

(2016). The reality of virtual anthropology: Comparing digitizer and laser scan data collection methods for the quantitative assessment of the cranium. American Journal of Physical Anthropology, 160, 148-155.

Ashley, S.

(1991). Rapid prototyping systems. Mechanical Engineering, 113, 34.

Athreya, S.

(2009). A comparative study of frontal bone morphology among Pleistocene hominin fossil groups. Journal of Human Evolution, 57, 786-804.

Barker, T. M., Earwaker, W. J. S., \& Lisle, D. A.

(1994). Accuracy of stereolithographic models of human anatomy. Australasian Radiology, 38, 106-111.

Benazzi, S., Gruppioni, G., Strait, D. S., \& Hublin, J. J.

(2014). Technical note: Virtual reconstruction of KNM-ER 1813 Homo habilis cranium. American Journal of Physical Anthropology, 153, 154-160.

Benazzi, S., Stansfield, E., Milani, C., \& Gruppioni, G.

(2009). Geometric morphometric methods for three-dimensional virtual reconstruction of a fragmented cranium: the case of Angelo Poliziano. International Journal of Legal Medicine, 123, 333-344. 
Berger, L. R., Hawks, J., de Ruiter, D. J., Churchill, S. E., Schmid, P., Delezene, L. K., et al.

(2015). Homo naledi, a new species of the genus Homo from the Dinaledi Chamber, South Africa. eLife, 4, e09560.

Bermúdez de Castro, J. M., Martín-Francés, L., Modesto-Mata, M., Martínez de Pinillos, M., Martinón-Torres, M., García-Campos, C., et al.

(2016). Virtual reconstruction of the Early Pleistocene mandible ATD6-96 from Gran Dolina-TD6-2 (Sierra De Atapuerca, Spain). American Journal of Physical Anthropology, 159, 729-736.

Bookstein, F. L.

(1991). Morphometric tools for landmark data: Geometry and biology. Cambridge: Cambridge University Press.

Bookstein, F., Slice, D., Gunz, P., \& Mitteroecker, P.

(2004). Anthropology takes control of morphometrics. Collegium Antropologicum, 28, 121-132.

Bookstein, F. L., \& Weber, G. W.

(2011). Virtual anthropology: A guide to a new interdisciplinary field. London: Springer.

Bowron, E. L.

(2003). A new approach to the storage of human skeletal remains. The Conservator, 27, 95-106.

Boyer, D. M., Puente, J., Gladman, J. T., Glynn, C., Mukherjee, S., Yapuncich, G. S., et al.

(2015). A new fully automated approach for aligning and comparing shapes. The Anatomical Record, 298, 249-276.

Buie, H. R., Campbell, G. M., Klinck, R. J., MacNeil, J. A., \& Boyd, S. K.

(2007). Automatic segmentation of cortical and trabecular compartments based on a dual threshold technique for in vivo micro-CT bone analysis. Bone, $41,505-515$.

Blender-A 3D modelling and rendering package. http://www.blender.org.

Choi, J. Y., Choi, J. H., Kim, N. K., Kim, Y., Lee, J. K., Kim, M. K., et al.

(2002). Analysis of errors in medical rapid prototyping models. International Journal of Oral and Maxillofacial Surgery, 31, 23-32.

Cohen, A., Laviv, A., Berman, P., Nashef, R., \& Abu-Tair, J.

(2009). Mandibular reconstruction using stereolithographic 3-dimensional printing modeling technology. Oral Surgery, Oral Medicine, Oral Pathology, Oral Radiology, and Endodontology, 108, 661-666.

Conroy, G. C., \& Vannier, M. W.

(1984). Noninvasive three-dimensional computer imaging of matrix-filled fossil skulls by high-resolution Computed Tomography. Science, 226, 456-458. 
Copes, L. E., Lucas, L. M., Thostenson, J. O., Hoekstra, H. E., \& Boyer, D. M.

(2016). A collection of non-human primate computed tomography scans housed in MorphoSource, a repository for 3D data. Scientific Data, 3, 160001.

Covino, S. W., Mitnick, R. J., Shprintzen, R. J., \& Cisneros, G. J.

(1996). The accuracy of measurements of three-dimensional computed tomography reconstructions. Journal of Oral and Maxillofacial Surgery, 54, 982990.

Dobson, C. A., Fagan, M. J., O’Higgins, P., \& Watson, P. J.

(2011). Validation of a morphometric reconstruction technique applied to a juvenile pelvis. Proceedings of the Institution of Mechanical Engineers. Part H, Journal of Engineering in Medicine, 225, 48-57.

Dunmore, C. J., Wollny, G., \& Skinner, M. M.

(2018). MIA-clustering: A novel method for segmentation of paleontological material. PeerJ, 6, e4374.

Ebert, L. C., Thali, M. J., \& Ross, S.

(2011). Getting in touch-3D printing in forensic imaging. Forensic Science International, 211, e1-e6.

Fedorov, A., Beichel, R., Kalpathy-Cramer, J., Finet, J., Fillion-Robin, J. C., Pujol, S., et al.

(2012). 3D Slicer as an image computing platform for the Quantitative Imaging Network. Magnetic Resonance Imaging, 30, 1323-1341.

Fontana, R., Greco, M., Materazzi, M., Pampaloni, E., Pezzati, L., Rocchini, C., et al.

(2002). Three-dimensional modelling of statues: The Minerva of Arezzo. Journal of Cultural Heritage, 3, 325-331.

Fourie, Z., Damstra, J., Gerrits, P. O., \& Ren, Y.

(2011). Evaluation of anthropometric accuracy and reliability using different three-dimensional scanning systems. Forensic Science International, 207, $127-134$.

Friess, M.

(2010). Calvarial shape variation among Middle Pleistocene hominins: An application of surface scanning in palaeoanthropology. Comptes Rendus Palevol, 9, 435-443.

Gallo, A., Muzzupappa, M., \& Bruno, F.

(2014). 3D reconstruction of small sized objects from a sequence of multi-focused images. Journal of Cultural Heritage, 15, 173-182.

Gunz, P.

(2005). Statistical and geometric reconstruction of hominid crania: Reconstructing australopithecine ontogeny. PhD. University of Vienna. 
Gunz, P., Mitteroecker, P., \& Bookstein, F. L.

(2005). Semilandmarks in three dimensions. In D. E. Slice (Ed.), Modern Morphometrics in Physical Anthropology (pp. 73-98). New York: Kluwer Academic/Plenum Publishers.

Gunz, P., Mitteroecker, P., Bookstein, F. L., \& Weber, G. W.

(2004). Computer aided reconstruction of incomplete human crania using statistical and geometrical estimation methods. In Enter the past: Computer applications and quantitative methods in archaeology (pp. 96-98). Oxford: BAR International Series.

Gunz, P., Mitteroecker, P., Neubauer, S., Weber, G. W., \& Bookstein, F. L.

(2009). Principles for the virtual reconstruction of hominin crania. Journal of Human Evolution, 57, 48-62.

Guyomarc'h, P., Santos, F., Dutailly, B., Desbarats, P., Bou, C., \& Coqueugniot, H.

(2012). Three-dimensional computer-assisted craniometrics: A comparison of the uncertainty in measurement induced by surface reconstruction performed by two computer programs. Forensic Science International, 219, 221-227.

Harvati, K., Frost, S. R., \& McNulty, K. P.

(2004). Neanderthal taxonomy reconsidered: Implications of 3D primate models of intra- and interspecific differences. Proceedings of the National Academy of Sciences, 101, 1147-1152.

Hawks, J., Elliott, M., Schmid, P., Churchill, S. E., de Ruiter, D. J., Roberts, E. M., et al.

(2017). New fossil remains of Homo naledi from the Lesedi Chamber, South Africa. eLife, 6, e24232.

Hildebolt, C. F., \& Vannier, M. W.

(1988). Three-dimensional measurement accuracy of skull surface landmarks. American Journal of Physical Anthropology, 76, 497-503.

Hildebolt, C. F., Vannier, M. W., \& Knapp, R. H.

(1990). Validation study of skull three-dimensional computerized tomography measurements. American Journal of Physical Anthropology, 82, 283-294.

Hirschmuller, H., \& Hirschmuller, H.

(2005). Accurate and efficient stereo processing by semi-global matching and mutual information. In 2005 IEEE computer society conference on computer vision and pattern recognition (CVPR'05) (Vol. 2, pp. 807-814).

Hirst, C.

(2017). British Museum exhibition review: The Jericho Skull, creating an ancestor. Papers from the Institute of Archaeology, 27, p. 7.

Hirst, C., White, S., \& Smith, S. E.

(2018). Standardisation in 3D geometric morphometrics: Ethics, ownership, and methods. Archaeologies. https://doi.org/10.1007/s11759-018-9349-7. 
Hjalgrim, H., Lynnerup, N., Liversage, M., \& Rosenklint, A.

(1995). Stereolithography: Potential applications in anthropological studies. American Journal of Physical Anthropology, 97, 329-333.

Holliday, T. W., Hutchinson, V. T., Morrow, M. M., \& Livesay, G. A.

(2010). Geometric morphometric analyses of hominid proximal femora: taxonomic and phylogenetic considerations. Homo, 61, 3-15.

Howells, W. W.

(1973). Cranial variation in man: A study by multivariate analysis of patterns of differences among recent human populations. Papers of the Peabody Museum: Harvard, Cambridge.

Huber, A.

(2014). Broken bones: Digital curation and mending of human remains. Bulletin of the Archaeological Society of Virginia, 69, 37-45.

Hublin, J. J.

(2013). Free digital scans of human fossils. Nature, 497, 183.

Hull, C.

(1986). Apparatus for production of three-dimensional object by stereolithography. U.S. Patent No. 4575330 A.

Jaklič, A., Erič, M., Mihajlović, I., Stopinšek, Ž., \& Solina, F.

(2015). Volumetric models from 3D point clouds: The case study of sarcophagi cargo from a $2 \mathrm{nd} / 3$ rd century AD Roman shipwreck near Sutivan on island Brač, Croatia. Journal of Archaeological Science, 62, 143-152.

Jung, H., Kim, H.-J., Kim, D.-O., Hong, S.-I., Jeong, H.-K., Kim, K.-D., et al.

(2002). Quantitative analysis of three-dimensional rendered imaging of the human skull acquired from multi-detector row computed tomography. Journal of Digital Imaging, 15, 232-239.

Kalvin, A. D., Dean, D., Hublin, J. J., \& Braun, M.

(1992). Visualization in anthropology: Reconstruction of human fossils from multiple pieces. In Proceedings of the 3rd Conference on Visualization, 1992 (pp. 404-410).

Kalvin, A. D., Kalvin, A. D., \& Dean, D.

(1995). Reconstruction of human fossils. IEEE Computer Graphics and Applications, 15, 12-15.

Katz, D., \& Friess, M.

(2014). Technical note: 3D from standard digital photography of human crania-Preliminary assessment. American Journal of Physical Anthropology, 154, 152-158.

Keklikoglou, K., Faulwetter, S., Chatzinikolaou, E., Michalakis, N., Filiopoulou, I., Minadakis, N., et al.

(2016). Micro-CT(vlab): A web based virtual gallery of biological specimens using X-ray microtomography (micro-CT). Biodiversity Data Journal, 4, e8740. 
Lorensen, W. E., \& Cline, H. E.

(1987). Marching cubes: A high resolution 3D surface construction algorithm. SIGGRAPH Computer Graphics, 21, 163-169.

Lynnerup, N., Hjalgrim, H., Nielsen, L. R., Gregersen, H., \& Thuesen, I.

(1997). Non-invasive archaeology of skeletal material by CT scanning and threedimensional reconstruction. International Journal of Osteoarchaeology, 7, 91-94.

Mankovich, N. J., Cheeseman, A. M., \& Stoker, N. G.

(1990). The display of three-dimensional anatomy with stereolithographic models. Journal of Digital Imaging, 3, 200.

McNulty, K., \& Smith, H. M.

(2009). Data were collected from high quality casts. Paleoanthropology Society Meeting Abstracts, 31 March \& 1 April 2009: Chicago, p. A25.

Means, B. K., McCuiston, A., \& Bowles, C.

(2013). Virtual artifact curation of the historical past and the NextEngine desktop 3D scanner. Technical Briefs in Historical Archaeology, 6, 1-12.

MeshLab (v1.3.3). http://meshlab.sourceforge.net.

Milella, M., Zollikofer, C. P. E., \& Ponce de León, M. S.

(2015). Virtual reconstruction and geometric morphometrics as tools for paleopathology: A new approach to study rare developmental disorders of the skeleton. The Anatomical Record, 298, 335-345.

Mitteroecker, P., \& Gunz, P.

(2009). Advances in geometric morphometrics. Evolutionary Biology, 36, 235247.

Noya, N. C., García, Á. L., \& Ramírez, F. C.

(2015). Combining photogrammetry and photographic enhancement techniques for the recording of megalithic art in north-west Iberia. Digital Applications in Archaeology and Cultural Heritage, 2, 89-101.

Ogihara, N., Nakatsukasa, M., Nakano, Y., \& Ishida, H.

(2006). Computerized restoration of nonhomogeneous deformation of a fossil cranium based on bilateral symmetry. American Journal of Physical Anthropology, 130, 1-9.

Pletinckx, D.

(2011). Virtual archaeology as an integrated preservation method. Virtual archaeology review, 2, 33-37.

Polo, M. E., \& Felicísimo, A. M.

(2012). Analysis of uncertainty and repeatability of a low-cost 3D laser scanner. Sensors (Basel), 12, 9046-9054. 
Ponce De León, M. S., \& Zollikofer, C. P. E.

(1999). New evidence from Le Moustier 1: Computer-assisted reconstruction and morphometry of the skull. The Anatomical Record, 254, 474-489.

Ponce de León, M. S., \& Zollikofer, C. P. E.

(2001). Neanderthal cranial ontogeny and its implications for late hominid diversity. Nature, 412, 534-538.

Ponce de León, M. S., Zollikofer, C. P. E., \& Flisch, A.

(2011). Homing in on stone: New insights from a virtual reconstruction of the Steinheim cranium. American Journal of Physical Anthropology, 144, 241242.

R: A Language and Environment for Statistical Computing.

(2014). http://www.R-project.org/.

Remondino, F.

(2011). Heritage recording and 3D modeling with photogrammetry and 3D scanning. Remote Sensing, 3, 1104.

Richtsmeier, J.

(1995). Precision, repeatability, and validation of the localization of cranial landmarks using Computed-Tomography scans. The Cleft Palate-Craniofacial Journal, 32, 217-227.

Rodríguez-Martín, M., Rodríguez-Gonzálvez, P., Lagüela, S., \& González-Aguilera, D.

(2016). Macro-photogrammetry as a tool for the accurate measurement of three-dimensional misalignment in welding. Automation in Construction, 71(Part 1), 189-197.

Rohlf, F. J., \& Rohlf, D.

(1990). Extensions of the Procrustes method for the optimal superimposition of landmarks. Systematic Zoology, 39, 40-59.

Ross, A. H., \& Williams, S.

(2008). Testing repeatability and error of coordinate landmark data acquired from crania. Journal of Forensic Sciences, 53, 782-785.

Rueden, C. T., Hiner, M. C., \& Eliceiri, K. W.

(2016). ImageJ: Image analysis interoperability for the next generation of biological image data. Microscopy and Microanalysis, 22, 2066-2067.

Rueden, C. T., Schindelin, J., Hiner, M. C., DeZonia, B. E., Walter, A. E., Arena, E. T., et al.

(2017). Image J2: ImageJ for the next generation of scientific image data. BMC Bioinformatics, 18, 529.

Sansoni, G., Cattaneo, C., Trebeschi, M., Gibelli, D., Porta, D., \& Picozzi, M.

(2009). Feasibility of contactless 3D optical measurement for the analysis of bone and soft tissue lesions: New technologies and perspectives in forensic sciences. Journal of Forensic Sciences, 54, 540-545. 
Schneider, C. A., Rasband, W. S., \& Eliceiri, K. W.

(2012). NIH Image to ImageJ: 25 years of image analysis. Nature Methods, 9, 671.

Seidler, $\mathrm{H}$.

(1997). A comparative study of stereolithographically modelled skulls of Petralona and Broken Hill: Implications for future studies of middle Pleistocene hominid evolution. Journal of Human Evolution, 33, 691-703.

Senck, S., Bookstein, F. L., Benazzi, S., Kastner, J., \& Weber, G. W.

(2015). Virtual reconstruction of modern and fossil hominoid crania: Consequences of reference sample choice. The Anatomical Record: Advances in Integrative Anatomy and Evolutionary biology, 298, 827-841.

Senck, S., Coquerelle, M., Weber, G. W., \& Benazzi, S.

(2013). Virtual reconstruction of very large skull defects featuring partly and completely missing midsagittal planes. The Anatomical Record: Advances in Integrative Anatomy and Evolutionary biology, 296, 745-758.

Sholts, S. B., Flores, P. L., Walker, S. K. T. S., \& Wärmländer,

(2011). Comparison of coordinate measurement precision of different landmark types on human crania using a 3D laser scanner and a 3D digitiser: Implications for applications of digital morphometrics. International Journal of Osteoarchaeology, 21, 535-543.

Simon, K. M., Payne, A. M., Cole, K., Smallwood, C. S., Goodmasters, C., \& Limp, F.

(2009). Close-range 3D laser scanning and virtual museums: Beyond wonder chambers and cabinets of curiosity? In Proceedings of Computer Applications and Quantitative Methods in Archaeology (CAA): Williamsburg, Virginia.

Smith, S. E., \& Hirst, C.

(2018). 3D data in human remains research. In Errickson, D., \& Marquez-Grant, N. (Eds.), Bioarchaeology: Ethical considerations. New York: Springer.

Spoor, C. F., Zonneveld, F. W., \& Macho, G. A.

(1993). Linear measurements of cortical bone and dental enamel by computed tomography: Applications and problems. American Journal of Physical Anthropology, 91, 469-484.

Streilein, A.

(1994). Towards automation in architectural photogrammetry: CAD-based 3Dfeature extraction. ISPRS Journal of Photogrammetry and Remote Sensing, 49, 4-15.

Thali, M. J., Braun, M., Brueschweiler, W., \& Dirnhofer, R.

(2003). 'Morphological imprint': Determination of the injury-causing weapon from the wound morphology using forensic 3D/CAD-supported photogrammetry. Forensic Science International, 132, 177-181. 
Tucci, G., Cini, D., \& Nobile, A.

(2011). Effective 3D digitization of archaeological artifacts for interactive virtual museum. In International archives of the photogrammetry, remote sensing and spatial information sciences (Vol. XXXVIII-5/W16, pp. 413-420).

Vannier, M. W., Conroy, G. C., Marsh, J. L., \& Knapp, R. H.

(1985). Three-dimensional cranial surface reconstructions using high-resolution computed tomography. American Journal of Physical Anthropology, 67, 299-311.

Weber, G. W.

(2001). Virtual anthropology (VA): A call for Glasnost in paleoanthropology. The Anatomical Record: Advances in Integrative Anatomy and Evolutionary Biology, 265, 193-201.

Weniger, G.-C.

(2005). NESPOS. A new scientific online platform. Presented at The world is in your eyes. Computer applications and quantitative methods in archaeology: Tomar, Portugal.

White, S.

(2016). The virtual revolution: Digital data and access in archaeology. Presented at WAC-8: Kyoto, Japan.

Wind, J.

(1984). Computerized X-ray tomography of fossil hominid skulls. American Journal of Physical Anthropology, 63, 265-282.

Ynnerman, A., Rydell, T., Antoine, D., Hughes, D., Persson, A., \& Ljung, P.

(2016). Interactive visualization of 3D scanned mummies at public venues. Communications of the ACM, 59, 72-81.

Zollikofer, C. P. E., Ponce de León, M. S., Lieberman, D. E., Guy, F., Pilbeam, D., Likius, A., et al.

(2005). Virtual cranial reconstruction of Sahelanthropus tchadensis. Nature, 434, 755-759.

Zollikofer, C. P. E., Ponce De León, M. S., \& Martin, R. D.

(1998). Computer-assisted paleoanthropology. Evolutionary anthropology: Issues, news, and reviews, 6, 41-54.

Zur Nedden, D., Knapp, R., Wicke, L., Judmaier, W., Murphy, W. A., Seidler, H., et al.

(1994). Skull of a 5,300-year-old mummy: Reproduction and investigation with CT-guided stereolithography. Radiology, 193, 269-272. 